\title{
CAPITU, A FIGURA FEMININA, NA OBRA DOM CASMURRO DE MACHADO DE ASSIS
}

Liporaci, Francine Pires ${ }^{1}$ COSTA, Sueli Silva Gorricho ${ }^{2}$

\begin{abstract}
RESUMO: Este trabalho propõe uma reflexão sobre a construção da personagem Capitu, apresentada na obra de Machado de Assis- Dom Casmurro (1899) do período literário do Realismo brasileiro. Procura-se enfatizar as regras de uma sociedade machista, onde as mulheres deveriam ser apenas esposas submissas e dedicadas; dentre essas mulheres se destaca a personagem Capitu por sua forte personalidade, representando uma mulher inteligente e sedutora, mas que nem com todos esses atributos é capaz de se desvencilhar do ciúme doentio de seu marido. Através de fragmentos da obra, buscamos compreender como se dá a construção de tal personagem, ressaltando o fato de Capitu não ter a oportunidade de se defender das acusações feitas por Bentinho. Buscamos fazer uma comparação entre Machado de Assis e o personagem Bentinho para que se possa melhor compreender a obra.
\end{abstract}

Palavras-chave: Capitu. Dom Casmurro. A figura feminina.

SUMMARY: This study proposes a reflection on the construction of the character Capitu presented in the work of Machado de Assis, Dom Casmurro (1899) of literary period of Brazilian Realism. We try to emphasize the rules of a male-dominated society where women should be submissive and devoted wives only; among these women highlights the character Capitu for her strong personality, representing an attractive and intelligent woman, but even with all these attributes she is not able to break away from insanely her husband's jealous. Through fragments of the work, we sought to understand how is the construction of such a character, considering the fact that Capitu do not have the chance to defend herself against Bento's accusations. We try to make a comparison between Machado de Assis and Bento so that we can better understand the work.

Keywords: Capitu. Dom Casmurro. The female figure.

\section{INTRODUÇÃO}

Este trabalho propõe uma reflexão sobre a personagem Capitu, da obra Dom Casmurro, de Machado de Assis. Procura-se focalizar o papel da mulher em uma sociedade em que a voz masculina ainda era mais forte. O tema leva a uma investigação dos referenciais bibliográficos e teóricos, apresentando um estudo crítico da obra. O objetivo dessa pesquisa é mostrar a construção da personagem Capitu, que mesmo sem expressar o que realmente pensa e sente, numa trama em que o olhar masculino retrata a desconfiança e o ciúme, não perde a altivez e a sua individualidade. A justificativa da escolha do tema se dá pela grande discussão em torno da personagem Capitu, que após anos da publicação da obra, ainda levanta discussões entre os leitores a ironia proposta por Machado de Assis. Muitos ainda se perguntam se Capitu traiu ou não Bentinho? Ou se tudo não passou de mera ilusão de um homem ciumento.

\section{Dom Casmurro, a obra}

Na obra Dom Casmurro (1899), o personagem Bento Santiago (Bentinho), narra seu romance com Capitolina (Capitu). Na infância eram vizinhos e não se desgrudavam, viviam brincando de fazer

\footnotetext{
${ }^{1}$ Licenciatura Plena em Letras - FE/FFCL. Ituverava-SP

${ }^{2}$ Prof. ${ }^{a}$ Me. do Curso de Letras - Literatura Brasileira - e Pedagogia - Literatura Infantil - da FFCL
} 
missa e dividiam a hóstia, prometeram se casar quando fossem adultos. Então, sua mãe Dona Glória percebendo que estava surgindo um romance, decidi mandar Bentinho para o Seminário, por conta de uma promessa que havia feito. Passado alguns anos, com a ajuda do agregado José Dias, Bentinho sai do Seminário, vai para a faculdade e se forma em Direito. Casa-se em seguida com Capitu, seu amor da adolescência. Recebe em sua nova casa visitas contínuas do seu amigo de seminário Escobar, que agora é casado com Sancha Gurgel, amiga de infância de Capitu. Escobar morre, e no velório, Bentinho fica perturbado pela postura de Capitu, naquele momento nasce a sua desconfiança, então ele começa a identificar indícios de uma provável traição.

\section{Capitu, a personagem}

Capitolina mais conhecida como Capitu é uma menina esperta, inteligente, de origem humilde, e dona de uma beleza encantadora. De personalidade forte, é prática e às vezes dissimulada, sobressai-se facilmente de situações difíceis. Morava na Rua de Matacavalos, era vizinha de Bentinho, desde crianças não se desgrudavam um do outro, com tanta proximidade acabam se apaixonando, então fazem a promessa de se casarem.

Sobre a personalidade de Capitu, Pereira (1988, p.33) diz, "Capitu, felina, ondulante, cheia de manhas e recursos, já se revelava, desde então, mulher até a ponta dos dedos." Mesmo menina já se mostrava a mulher que seria muito diferente das mulheres de sua época ela não seria submissa e nem ao menos desistiria de seus desejos.

Bentinho descreve com detalhes as características físicas de sua vizinha, da qual não conseguia tirar os olhos, pois ela o fascinava.

Não podia tirar os olhos daquela criatura de catorze anos, forte e cheia, apertada em um vestido de chita, meio desbotado. Os cabelos grossos, feitos em duas tranças, com as pontas atadas uma á outra, à moda do tempo, desciam-lhe pelas costas. Morena, olhos claros e grandes, nariz reto e comprido, tinha a boca fina e o queixo largo. (ASSIS, 1994. p.20)

Apesar de vários contratempos, ela luta para ficar ao lado de Bentinho, mas o ciúme e a desconfiança dele acabam afastando o casal.

\section{A construção da personagem}

Para entender a personagem Capitu é necessário refletir sobre o contexto sócio histórico em que ela está inserida (por volta dos anos de 1850 em diante), na fase final do Império. Se ainda as mulheres não tinham muito o direito de pensar, viviam dentro de casa, aprendendo trabalhos domésticos e como ser uma boa mãe e esposa; não trabalhavam fora e deveriam ser obedientes aos seus maridos. Um período de transição se anuncia com o início do capitalismo e da urbanização do país. A mulher começa a avançar além das fronteiras domésticas e a ocupar um espaço maior na sociedade. Surgem então mulheres escritoras, jornalistas, professoras e cortesãs etc.

Capitu se destaca entre essas mulheres, ela se mostra à frente de seu tempo, por sua postura e inteligência, muito perspicaz, dissimulada, com seu jeito feminino se sobressai de situações complicadas, deixa um pouco a ingenuidade de lado para lutar pelo seu amor Bento Santiago.

Sobre o papel desempenhado pela personagem dentro da obra, Candido (1998, pg.45) ressalta: "Como seres humanos encontram-se integrados num denso tecido de valores de ordem cognoscitiva, religiosa, moral, político-social e tomam determinadas atitudes em face desses valores". 
Assim, pode se dizer que a personagem vive dentro de um ambiente social em que se espera que ela respeite as regras, vivendo dentro de uma moral aceita pela sociedade. Bentinho procura mostrar que a Capitu adulta, já existia na adolescência.

E séria, fitou em mim os olhos, convidando-me ao jogo. O susto é naturalmente sério; eu estava ainda sobe a ação do que trouxe a entrada de Pádua, e não fui capaz de rir, por mais que devesse fazê-lo, para legitimar a resposta de Capitu. Esta, cansada de esperar, desviou o rosto, dizendo que eu não ria daquela vez por estar ao pé do pai. E nem assim ri. Há coisas que só se aprendem tarde; é mister nascer com elas para fazê-las cedo.(ASSIS,1994. p.23)

Nesse trecho acima, Capitu e Bentinho são flagrados pelo pai dela de mãos dadas, mesmo sendo essa uma situação constrangedora, na qual Bentinho permanece calado por estar nervoso; Capitu toma a frente na situação dando uma resposta rápida ao pai, mentindo facilmente que estavam jogando siso.

A reflexão também faz parte de Capitu, ela analisa tudo com cautela, como mostra na cena em que Bentinho conta para ela que irá para o seminário.

Capitu refletia. A reflexão não era coisa rara nela, e conheciam-se as ocasiões pelo apertado dos olhos. Pediu-me algumas circunstâncias mais, as próprias palavras de uns e de outros, e o tom delas. (ASSIS, 1994, p.29)

Há também a visão que outros personagens tinham de Capitu. No Capítulo 22, Prima Justina em uma conversa com Bentinho faz alguns elogios à menina, mas não deixa de dizer algumas críticas, como ela era um pouco trefega e que olhava por baixo. O que leva o leitor a refletir que mesmo sendo tão carinhosa, bonita e prestativa, Capitu é também astuta, sagaz e ardilosa. José Dias também faz algumas críticas:

Capitu, apesar daqueles olhos que o diabo lhe deu... Você já reparou nos olhos dela? São assim de cigana obliqua e dissimulada. Pois, apesar deles poderia passar se não fosse a vaidade e a adulação. (ASSIS, 1994, p.38)

Ele a descreve como uma pessoa oblíqua pelo fato de ser maliciosa, astuta, fingida, e que tem o intuito de agradar as pessoas para colher vantagens, sabendo simular sentimentos e emoções.

Bentinho também descreve os olhos de Capitu. "Retórica dos namorados, dá-me uma comparação exata e poética para dizer o que foram aqueles olhos de Capitu. [...] Olhos de ressaca? Vá, de ressaca." (ASSIS, 1994, p.51). São olhos misteriosos, que atraem e têm a capacidade de envolver e tragar como as ondas do mar nos dias de ressaca.

Capitu é descrita como minuciosa e atenta, muito curiosa, gostava de saber de tudo, coisas de maior importância ou mesmo inúteis, mas sempre desejava por explicações sobre o desconhecido, buscava transcender o conhecimento básico das coisas e queria saber sempre mais.

Dom Casmurro utiliza trechos, de lembranças do passado para trazer dúvidas para o leitor, sobre a moral de Capitu e sua traição, relembrando impressões de pessoas que não gostavam dela.

Para Candido (1968, p.73), Machado de Assis em relação aos personagens procura,

Em tais casos, as personagens obedecem a uma certa concepção de homem, a um intuito simbólico, a um impulso indefinível, ou quaisquer outros estímulos de base, que o autor corporifica, de maneira a supormos uma espécie de arquétipo que, embora nutrido da experiência de vida e da observação, é mais interior do que exterior. Seria o caso dos personagens de Machado de Assis- em geral homens feridos pela realidade e encarando a com desencanto. 
Este é exatamente o caso de Bentinho, que ferido pela suposta traição, procura por meio de fatos buscar o caráter duvidoso de Capitu, mas não se deve esquecer "que a visão de um ser elaborada por outro ser, é sempre incompleta", como cita Candido (1998, p. 56).

Não se pode ter certeza de que Capitu é exatamente como descreve Bentinho, afinal só se sabe o que ele pensa e diz, são suas lembranças misturadas aos ciúmes e à desconfiança de tantos anos. Por meio de trechos da fase adulta do casal, pode-se perceber isso:

Venho explicar-te que tive tais ciúmes pelo que podia estar na cabeça de minha mulher, não fora ou acima dela. É sabido que as distrações de uma pessoa podem ser culpadas, metade culpadas, um terço, um quinto, um décimo de culpadas, pois em matéria de culpa a graduação é infinita. (ASSIS, 1994, p. 148)

O casal está conversando, e num momento de distração de Capitu que estava olhando o mar, Bentinho sente ciúmes, faz suposições se ela estaria pensando em algo que ele não deveria saber, indaga porque não presta atenção nele. Isso mostra o quanto o ciúme o controlava.

Outro momento de ciúmes é quando Bentinho e Capitu vão ao baile, e os braços de sua esposa estão à mostra. "Cheguei a ter ciúmes de tudo e de todos. Um vizinho, um par de valsa, qualquer homem, moço ou maduro, me enchia de terror ou desconfiança." (ASSIS, 1994,p. 156).

Um momento que marca a tensão da obra é o velório de Escobar, pois nesse capítulo nasce em Bentinho a dúvida da traição.

Capitu olhou alguns instantes para o cadáver tão fixa, tão apaixonadamente fixa, que não admira lhe saltassem algumas lágrimas poucas e caladas... Momento houve em que os olhos de Capitu fitaram o defunto quais os da viúva, sem o pranto nem palavras desta, mas grandes e abertos, como a vaga do mar lá fora, como se quisesse tragar também o nadador da manhã. (ASSIS, 1994, p.167)

A partir desse momento muda-se totalmente a relação do casal, Bentinho perante a reação de sua mulher diante do cadáver de seu amigo, fica indignado, e a cada dia que passa enxerga uma semelhança inegável de seu filho Ezequiel com Escobar.

A personagem é vista por seus leitores através do olhar que o seu autor permite, é ele quem mostra determinadas situações, assim percorremos o mesmo caminho do autor, mas depende do leitor aceitar ou não como verdade tudo o que está escrito.

É precisamente o modo pelo qual o autor dirige o nosso "olhar", através de aspectos selecionados de certas situações, da aparência física e do comportamento, - ou diretamente através de aspectos da intimidade das personagens. (CANDIDO, 1998, p.35)

É o que acontece com Capitu, seu comportamento, suas reações, tudo nos é mostrado através do olhar de outro personagem que tenta provar que a Capitu mulher sempre esteve naquela menina, esperta e inteligente.

A construção dessa personagem é magnífica, Capitu é dona de uma personalidade forte e marcante, inteligente, prática, sabe criar saídas em situações difíceis e se mantem assim por toda a obra, mesmo quando acusada de traição pelo seu marido enciumado, permanece altiva e não responde as acusações. Tudo isso deixa pairar no ar, a dúvida se ela cometeu ou não a traição.

Machado de Assis sendo um estudioso da alma humana, não poderia deixar de analisar essa personagem, que tem o poder de confundir até hoje os seus leitores, e através de Bentinho ele procura revelar quem ela é, narrando sua vida desde a infância. Como cita Candido (1998, p.59) "o autor nos faz seguir um único caminho para a interpretação, pois nos permite seguir uma linha de coerência fixada, 
delimitada nos modos de ser da personagem". A maneira como narra a história, leva o leitor a desconfiar da moral da personagem.

A sua combinação, a sua repetição, a sua evocação nos mais variados contextos nos permite formar uma ideia completa, suficiente e convincente daquela forte criação fictícia. (CANDIDO, 1998, p.58)

$\mathrm{Na}$ sua totalidade, a obra trata de uma ironia. A ironia ("do grego eironeia, que significa "dissimulação") ou antífase ("do grego antíphases, que quer dizer "expressão contrária") é um alargamento semântico. É preciso ler a obra com os olhos atentos, de uma maneira mais profunda, e não se fixar apenas num primeiro plano. Deve-se considerar os dois lados da história. Capitu é intitulada como dissimulada, mas Bentinho também utiliza da dissimulação, o que mostra essa ironia, ele faz isso para dar destaque ao seu próprio ponto de vista, com o objetivo de convencer o leitor de que suas dúvidas tinham fundamento.

\section{O olhar feminino: olhos de ressaca}

Os olhos e olhares femininos exerceram grande fascínio sobre Machado de Assis, a julgar por varias criações que lhe confere um papel decisivo e mesmo tirânico de sedução amorosa... A metáfora "olhos de ressaca" descreve o olhar de Capitu, nesse romance, os olhos das personagens atuam em si quase sempre de maneira estranha quando não mesmo importuna, como arma de efeito a distância. (GOMES, 1967, p.99)

Machado de Assis procurou destacar o olhar feminino em sua obra, e esse olhar descreve suas personagens em vários momentos, como acontece com Capitu, que é por vezes mencionada por conta de seu olhar, ele também define os olhos como sendo a janela da alma humana, e dá a eles um grande poder de sedução.

A expressão "Olhos de ressaca" é uma metáfora que marca a personagem Capitu. Quando se fala em ressaca, a primeira coisa que vêm à cabeça é a visão do mar com suas águas revoltas, tragando tudo o que vier pela frente com uma força imensa, força essa que um homem em sã consciência não enfrentaria.

Capitu seria a representação dessa força, pois ela assim como o mar, não se detém com obstáculos. E assim como as ondas, o seu olhar é hipnotizante. Bentinho procura buscar uma definição para os olhos de Capitu, após José Dias fazer uma sugestão bem maliciosa sobre eles:

Olhos de ressaca? Vá de ressaca. É o que me dá ideia daquela feição nova. Traziam não sei que fluido misterioso e enérgico, uma força que arrastava para dentro, como a vaga que se retira da praia, nos dias de ressaca. Para não ser arrastado, agarrei-me às outras partes vizinhas, às orelhas, aos braços, aos cabelos espalhados pelos ombros; mas tão depressa buscava as pupilas, a onda que me saia delas vinha crescendo, cava e escura, ameaçando envolver-me, puxar-me e tragar-me. (ASSIS, 1994, p.51).

Bentinho sente-se sendo tragado pelo olhar de Capitu, como se ele estivesse entrando num naufrágio de onde dificilmente conseguiria se salvar, nesse momento o autor retrata a força de sedução que tinham os olhos da personagem, e Bentinho só consegue se livrar dessa força que o arrasta, por se agarrar aos cabelos de sua amada.

A partir dessa metáfora, olhos de ressaca, Bentinho para contar sua vida em diferentes momentos, como na morte de Escobar, em que ele diz que os olhos de Capitu eram grandes e abertos, assim como o mar que havia tragado seu amigo. Também descreve suas brigas com a esposa como temporais contínuos e terríveis. 
Segundo Gomes (1967, p.102), existe uma comparação da metáfora "olhos de ressaca" utilizada por Machado de Assis, com a imagem Shakespeariana "pérfida como a onda", que seria uma relação com os mitos do mar, como as sereias ou monstros marinhos, que encantavam os marinheiros com sua linda voz, ou com apenas um olhar os deixariam petrificados, sendo a única intenção levá-los para o fundo do mar, onde morreriam afogados.

Essa semelhança com as sereias se remete mais uma vez à personagem Capitu, que tinha o dom de encantar e envolver as pessoas, a partir de sua beleza e dissimulação. Portanto, a metáfora "olhos de ressaca" denota a personalidade de Capitu, que assim como o mar, é oscilante, encantador, mas perigoso.

\section{As semelhanças: o retrato}

Entre as imagens visões que se entrecruzam no momento verdadeiramente crítico da experiência conjugal de D. Casmurro adquirem extraordinária significação as que provêm do retrato. (GOMES, 1967, p.127)

De acordo com Gomes (1967), o fim do casamento entre Bento Santiago e Capitu se deve à provável traição da esposa, que teria como prova a suposta semelhança entre Ezequiel e Escobar.

No capítulo "O Retrato", ocorre uma conversa entre Gurgel, pai de Sancha, e Bentinho. Ele mostra para Bentinho, ainda um menino na época, um retrato de sua falecida esposa e pergunta se ela não se parecia com Capitu. Bentinho como sempre concordava com todos para não desagradar, respondeu que sim, sem ao menos examinar melhor o retrato. Mas o que ficou em sua cabeça foi a última frase que Gurgel disse: "Na vida há dessas semelhanças assim esquisitas." (ASSIS, 1994. p.120)

Isso explica que é possível existir semelhança entre duas pessoas, mesmo elas não tendo nenhum vínculo de parentesco. Como era o caso de Capitu e a mãe de Sancha, já falecida. Para ressaltar a questão da semelhança Gomes (1967, p.163) diz:

A semelhança física de pessoas que não tem parentesco entre si é um fenômeno conhecido, existindo coincidências a esse respeito que são de estarrecer, como as dos sósias. Há, efetivamente, parecenças impressionantes e que são apenas obra do acaso... Há também o fenômeno correlato do subjetivismo de certas impressões visuais, que se formam por um ditame incoercível de simpatia.

Alguns anos depois, o casal tem seu primeiro e único filho, Ezequiel. Um menino muito esperto e inteligente, mas que muitas vezes chamavam-lhe a atenção por ficar imitando as pessoas, como o jeito de andar, e de conversar; as pessoas ao redor viam como uma brincadeira de criança, mas que com o tempo iria se corrigir. Mas uma indagação inocente de Capitu a respeito da semelhança, desperta em Bentinho novamente o ciúmes, ele começa então a duvidar da paternidade do filho, pois a semelhança entre o menino e seu amigo Escobar eram inegáveis.

-Você já reparou que Ezequiel tem nos olhos uma expressão esquisita?- perguntou-me Capitu. - Só vi duas pessoas assim, um amigo de papai e o defunto Escobar. Olha, Ezequiel; olha firme, assim, vira para o lado de papai, não precisa revirar os olhos, assim, assim...

Aproximei-me de Ezequiel, achei que Capitu tinha razão; eram os olhos de Escobar, mas não me pareceram esquisitos por isso. Afinal não haveria mais que meia dúzia de expressões no mundo, e muitas semelhanças se dariam naturalmente. (ASSIS, 1994, p. 174).

Ele concorda com o que Capitu diz a respeito da semelhança. Mas quando não está mais na presença da mulher, recai sobre ele a dúvida que sempre o atormentava desde a morte de Escobar. A partir 
desse momento ele enxerga as feições de Escobar surgindo em seu filho, como se o próprio amigo fosse se levantar do túmulo para sentar-se com ele à mesa de jantar.

Em busca de respostas, ele olha para um retrato que tinha de Escobar, e tem a certeza que o menino era o retrato do amigo. Assim, no capítulo trinta e sete, num momento de desespero pensa em colocar veneno em uma xícara de café, mas com a chegada do menino é interrompido, pensa em fazer algo pior, tirar a vida do menino fazendo com que ele bebesse o café. Desistindo no último instante, deixa a xícara de lado, beija a cabeça do menino e acaba dizendo que não era seu pai. Capitu então entra na sala.

Desta vez, ao dar com ela, não sei se era dos meus olhos, mas Capitu pareceu-me lívida. Seguiu-se um daqueles silêncios, a que, sem mentir, se podem chamar de um século, tal é a extensão do tempo nas grandes crises. Capitu recompôs-se; disse ao filho que se fosse embora, e pediu-me que lhe explicasse...

- Não há que explicar-disse eu.

- Há tudo; não entendo as tuas lágrimas nem as de Ezequiel. Que houve entre vocês?

- não ouviu o que lhe disse?

Capitu respondeu que ouvira choro e rumor de palavras. Eu creio que ouvira tudo claramente, mas confessá-lo seria perder a esperança do silêncio e da reconciliação; por isso negou a audiência e confirmou unicamente a vista. Sem lhe contar o episódio do café, repeti-lhe as palavras.

- O quê?- perguntou ela como se ouvira mal.

-Que não é meu filho.

Grande foi à estupefação de Capitu, e não menor a indignação que lhe sucedeu, tão naturais ambas que fariam duvidar as primeiras testemunhas de vista do nosso foro. [...] Assim que, sem atender à linguagem de Capitu, aos seus gestos, à dor que a retorcia, a coisa nenhuma, repeti as palavras ditas duas vezes com tal resolução que a fizeram afrouxar. Após alguns instantes, disse-me ela:

- Só se pode explicar tal injuria pela convicção sincera; entretanto, você, que era tão cioso dos menores gestos, nunca revelou a menor sombra de desconfiança. Que é que lhe deu tal ideia? Diga- continuou vendo que eu não respondia nada-, diga tudo; depois do que ouvi, posso ouvir o resto, não pode ser muito. Que é que lhe deu agora tal convicção? Ande Bentinho, fale! Fale! Despeça-me daqui, mas diga tudo primeiro.

- Há coisas que não se dizem.

- Que se não dizem só metade; mas, já que disse metade, diga tudo.

Tinha-se sentado numa cadeira ao pé da mesa. Podia estar um tanto confusa, o porte não era de acusada. Pedi-lhe ainda uma vez que não teimasse.

- Não, Bentinho, ou conte o resto, para que eu me defenda, se você acha que tenho defesa, ou peço-lhe desde já a nossa separação: não posso mais!

(ASSIS, 1994, p.181-182)

No momento da discussão entra Ezequiel na sala chamando a mãe para ir à missa, então, Bentinho sente confirmada sua dúvida, não havia como negar tal semelhança. Capitu, confusa, olha juntamente com Bentinho para Ezequiel e em seguida um para o outro. Ela não diz nada, pega o menino pela mão e sai para ir à igreja. Para um marido ciumento, o silêncio da esposa diante da situação serviu como uma confissão de culpa, como se ela não encontrasse maneiras de convencer o marido de que ele estava enganado com suas dúvidas.

A coincidente semelhança entre duas pessoas acaba por destruir o casamento de Capitu e Bentinho. Não existe a certeza da traição, pois Capitu se mantem silenciosa diante das acusações. O que provoca no leitor duas suposições, ela não diz nada porque realmente traiu o marido e não há mais como encobrir a mentira, ou se mantem em silêncio, pois se sente ofendida, sendo que toda sua vida provou que sempre amou Bentinho. Em todos os momentos essa personagem faz com que o leitor permaneça na dúvida, tentando buscar nos detalhes respostas para suas atitudes e comportamento. 


\section{Traição: a ideia fixa}

Durante toda a obra, permanece a dúvida sobre a moral da personagem Capitu, se realmente ela traiu ou não seu marido, se o seu filho era realmente de Escobar. Não existem provas sobre o crime de adultério, tampouco sobre a semelhança de Ezequiel. Mas Bentinho não se contenta somente com isso, mostrando para o leitor as opiniões de pessoas que desconfiavam da índole de Capitu.

O que intriga muitos leitores, é quem seria essa mulher que luta por seu amor, enfrenta obstáculos, capaz de seduzir, talvez até mesmo de trair seu marido. Capitu é apresentada através das palavras de Bentinho, "homem imaginativo em que o subjetivismo supera a visão direta da realidade propriamente dita". (GOMES, 1967, p.163)

Diante de tantas dúvidas, da suposta traição de sua mulher e seu amigo, da terrível semelhança de Ezequiel e Escobar, ele decide afastar Capitu e o filho, exilando-os definitivamente na Europa, onde Capitu falece e é enterrada. Logo após Ezequiel volta para o Brasil, sendo recebido friamente pelo pai de quem sentia saudades, não se demorando muito, parte numa expedição para Jerusalém, onde morre por conta de uma epidemia. Bentinho por fim, sozinho, afunda de vez em sua casmurrice.

Iniciando sua fixação em tentar reconstruir através de lembranças sua vida da adolescência até o fim trágico de seu casamento. Uma maneira de atar as duas pontas de sua vida. Mostrando que, por mais tragédias que tenham acontecido, nenhuma mulher se compara a Capitu, e que o ciúme doentio foi o início do fim de um grande amor.

Agora, porque é que nenhuma dessas caprichosas me fez esquecer a primeira amada do meu coração? Talvez porque nenhuma tinha os olhos de ressaca, nem os de cigana obliqua e dissimulada. Mas não é este propriamente o resto do livro. O resto é saber se a Capitu da praia da Glória já estava dentro da de Matacavalos, ou se esta foi mudada naquela por efeito de algum caso incidente. Jesus, filho de Sirach, se soubesse dos meus primeiros ciúmes, dir-me-ia, como no seu cap. IX, vers. 1: "Não tenhas ciúmes de tua mulher para que ela não se meta a enganar-te com a malícia que aprender de ti". (ASSIS, 1994, p.191)

Machado de Assis constrói essa personagem dentro de uma rede de intrigas, desconfiança e ciúmes, e mesmo não dando a ela a oportunidade de se defender, cria uma personalidade marcante.

Não foram necessárias a Machado de Assis cenas realistas para fazer entender que, no casamento, Capitu dominaria- mas não ficaria inteiramente satisfeita. Disse sem dizer, narrando o namoro ingênuo de duas crianças, esboçando-lhes os temperamentos. A arte que vai firmando os contornos de Bentinho e Capitu, por gradações imperceptíveis, só pode ser comparada à da natureza, ao crescimento das plantas, ao clarear dos dias. (PEREIRA, 1988, p.241).

Assim, segundo Pereira (1988), desde a adolescência fica claro que seria Capitu quem dominaria na relação, e Bentinho seria sempre aquele garoto tímido, emotivo, e acima de tudo ciumento. Essa diferença nítida entre eles deixaria sem dúvidas, lugar para a desconfiança e o ciúme, que se mostra frequente no decorrer de toda a obra.

\section{O olhar final}

Tratando-se de Machado de Assis, não há dúvidas de que ele soube atingir seu objetivo ao deixar o leitor, mesmo aquele mais atento, a ter dúvidas sobre a personalidade de Capitu. Afinal, como não ficar fascinado com essa mulher tão sedutora e misteriosa? Mas essa personagem ainda apresenta algumas 
características a serem apontadas. Segundo Gomes (1967), a personagem apresenta certa semelhança com a esposa de Machado de Assis, a portuguesa Carolina.

Capitolina e Carolina têm certa semelhança até mesmo no som de seus nomes, assim como a redução deles para Capitu e Carola. Mas as semelhanças não param por ai, vale ressaltar também as coincidências entre Machado e Bentinho.

O romancista desafiou, preliminarmente, uma temeridade fazendo a sua fase juvenil coincidir no espaço e no tempo com a de sua personagem, o pseudoautor da narrativa. [...] Um e outro atendiam por um carinhoso diminutivo familiar, respectivamente: Machadinho e Bentinho. O autor veio ao mundo antes de uma irmã, que morreu ainda criança; a personagem fora precedida de um natimorto. Os dois tiveram afinal a condição de filho único. (GOMES, 1967, p. 178-179)

Existem certas semelhanças e diferenças entre autor e personagem. Machado de Assis era negro e de origem humilde, mas foi reconhecido ainda em vida como autor consagrado, casou-se com Carolina Augusta Xavier de Novais. Já Bentinho nasceu em uma família de posses, fazendo parte da sociedade burguesa, casou-se com Capitu que pertencia a uma família de classe inferior à dele. Assim essa diferença, os distancia um pouco, deixando o autor incógnito.

Mas o que realmente merece destaque é o sentimento que Machado e Bentinho têm em comum: o ciúme, que Gomes (1967, p.181), ressalta a partir do testemunho da Sr. ${ }^{\text {a }}$ Francisca de Basto Cordeiro que conhecia o autor desde muito moço, "Machado de Assis não era apenas ciumento, mas ciumentíssimo, a ponto de não consentir que a mulher apertasse a mão aos amigos mais íntimos, até quase o fim da vida". Tão ciumento quanto sua criação literária, que é capaz de modificar até a mesmo a visão que tem da realidade, num desejo de completo exclusivismo sobre a mulher.

Lembrando que o Realismo, movimento literário no qual se encaixa esse romance, nada mais é do que colocarem na obra os traços da realidade, seja das pessoas ou de seus sentimentos. Machado pode ter colocado em Bentinho, justamente aquele sentimento que ele mesmo tinha de mais acentuado, seu ciúme por sua esposa.

Sobre esse aspecto Gomes (1967, p.182), ainda relembra algumas reflexões feitas pelo crítico Robert Liddell:

A grande fonte de criação de uma personagem é naturalmente o eu do próprio romancista. $\mathrm{O}$ escritor passando a viver em sua personagem despoja-se daquelas partes da sua natureza, que são irrelevantes, e desenvolve as que ultrapassam a linha do normal.

Assim, Bentinho apresenta parte dos ciúmes, existentes no próprio Machado. Capitu poderia então ser a representação de Carolina? Se assim o fosse, poderia vir a ser considerada inocente das acusações sofridas pelo marido, pois a esposa de Machado, segundo Gomes (1967) "A mulher de Machado de Assis, senhora digníssima, mais velha do que ele cinco anos, nunca the deu pretexto para ciúmes." Foi vista por todos como mulher de respeito e incapaz de cometer uma traição, sendo que o único problema seria o ciúme um tanto doentio do marido.

Capitu se foi dissimulada, se traiu ou não seu marido, se realmente é uma representação de Carolina, pouco importa, o que interessa ao leitor saber, é que essa personagem se destacou dentro da literatura de sua época, mostrando-se uma mulher altiva, sedutora, perspicaz e inteligente. Que lutou até onde pôde por seu amor, mas que sofreu por conta da desconfiança e do ciúme de seu marido. E que até hoje, basta se referir à metáfora "Olhos de ressaca", para que sua personagem seja logo lembrada. 


\section{CONSIDERAÇÕES FINAIS}

Capitu, personagem enigmática, envolvente e acima de tudo uma mulher. Contextualizada em um período em que desejos e opiniões femininos brotavam ao desabrochar de uma nova sociedade. Não se deve, portanto, ser analisada somente pelo olhar ciumento e possessivo de Bentinho, é preciso levar em consideração o fato de ser ocultada a argumentação de Capitu, e que a obra é uma maneira que Bentinho encontrou para convencer o leitor e a si mesmo que suas dúvidas tinham fundamentos. Isso faz com que a fala de Candido (1968, p. 73) tenha certo valor ao dizer que os homens encaram a realidade com desencanto quando são feridos.

As expressões, "olhos de ressaca" e "de cigana oblíqua e dissimulada", têm a força da metáfora que norteia outro olhar para uma realidade já pré-estabelecida em busca de respostas na comparação entre os personagens. Capitu com o seu silêncio e com uma personalidade forte, não tem a oportunidade de defender-se.

Portanto, falar de Capitu é refletir sobre a questão feminina em uma sociedade ainda machista, que se vale de metáforas para caracterizá-la.

Assim, este trabalho, não pretende encerrar a discussão sobre a culpa ou inocência de Capitu, se Bentinho tem razão ou não, mas deixa claro que não existe somente uma versão dos fatos, e que vários acontecimentos devem ser levados em consideração pelos leitores mais atentos, antes de julgarem a personagem por seus "olhos de cigana oblíqua e dissimulada".

\section{REFERÊNCIAS}

ASSIS, M. de. Dom Casmurro. $15^{\circ}$ ed. São Paulo: Ática, 1994. 192p.

BOSI, A. História concisa da literatura brasileira. São Paulo: Cultrix, 1994. 528p.

CANDIDO, A., et al. A personagem de ficção. 9.ed. São Paulo: Perspectiva, 1998. 119p.

CANDIDO, A. Esquema de Machado de Assis. In: Vários escritos. $2^{\circ}$ ed. São Paulo: Duas cidades, 1995.

CANDIDO, A, CASTELLO, J.A. Presença da Literatura Brasileira: Romantismo, Realismo,

Parnasianismo, Simbolismo. 5. ed. São Paulo: Difusão Europeia do Livro, 1974.

EAGLETON, T.. Teoria da literatura: uma introdução. Tradutor: DUTRA, Waltensir . São Paulo: Martins Fontes, 2001.

GOMES, E. O enigma de Capitu. Rio de Janeiro: José Olympio, 1967.

HOLANDA, A. Dicionário da língua portuguesa. 6.ed. rev. e atual. Curitiba: Positivo., 2005, p.519

LAJOLO, M. O que é literatura. São Paulo: Nova Cultural: Brasiliense, 1986.

PEREIRA, L. “Machado de Assis”. Belo Horizonte: Itatiaia; São Paulo: Edusp, 1988.

RELAÇÃO das obras de Machado de Assis. Disponível em:

http://www.suapesquisa.com/machadodeassis/. Acesso em: 23 mar. 2011. 